\title{
ANEURYSMAL BONE CYST - A CASE REPORT AND REVIEW OF THE LITERATURE
}

NZ Hussaini, $R$ Zain, ZA Rahman, MA Jalaludin. Aneurysmal bone cyst - a case report and review of the literature, Annals Dent Univ Malaya 1998; 5: 53-56

\section{ABSTRACT}

Aneurysmal bone cyst is a rare non-epithelialized pseudocyst of the jaws. Jaffe and Lichtenstein in 1942 were the first to recognize aneurysmal bone cyst as a distinct clinical and pathological entity while Bemier and Bhaskar in 1958 were the first to describe the presence of this lesion in the jaws. A case of aneursymal bone cyst in the maxilla is presented and the literature reviewed.

Keywords: Aneursymal bone cyst, maxilla

\section{INTRODUCTION}

Aneurysmal bone cyst $(\mathrm{ABC})$ has been described as a pseudocyst due to the absence of an epithelial lining. It is rarely found in the jaws and comprises of $1 \%$ of all nonepithelial and non odontogenic cysts of the jaws. It was first recognized as a distinct clinical and pathological entity by Lichtenstein et al in 1942 (1). However, the presence of this lesion in the jaws was first described by Bernier and Bhaskar (2) in 1958. Despite its recognition in the jaws since 1958, it is still an uncommon finding in the facial bones.

According to Jaffe, the word aneurysmal was used in relation to the blowout distension of part of the affected bone area $(1,2)$. The bony expansion usually causes visible swelling of the overlying soft tissues. Usually an intact periosteum and a very thin shell of bone covers the cyst. During surgery and upon removal of the bone shell, dark venous blood wells up and bleeding may be difficult to control. The aetiology and pathogenesis of this lesion is still debatable. It is the purpose of this paper to report one such case of aneurysmal bone cyst in the maxilla and to briefly review the literature.

\section{CASE REPORT}

A 14 year-old girl presented with a swelling of the left cheek of more than 6 months duration. A dental staff during a routine dental check first detected the swelling. Subsequently, she was advised to go to the Dental Department Elizabeth Hospital, Kota Kinabalu.

The swelling was present in her mouth for six months. There was no prior history of trauma or any factors that could contribute to the aetiology of the growth.

Generally, she was in good health with no medical problems except for the swelling, which extended from her left infra orbital rim down to her cheek excluding the mandibular area. There was slight proptosis of her left eye. The lesion was firm upon palpation.

Intra-orally, there was a mass present at her hard palate, which encroached upon her left alveolar ridge. Overlying mucosa was pink and smooth. Her upper left premolars and molars were mobile.

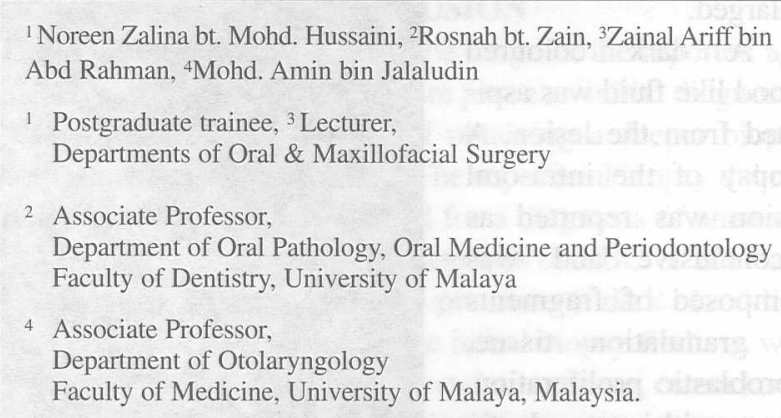

Radiographically, there was a radiopaque lesion present at the left maxillary antrum. It did not have a well-defined margin. There was discontinuity of the left infra-orbital rim (Figure 1). A computerized tomograpic (CT) scan showed that there was a huge heterogenous solid mass occupying the whole left half of the nasopharynx. Patchy enhancement was observed with intravenous contrast medium. Erosion and destruction of the lateral pterygoid plate extending to the pharyngeal space was present. There was also erosion of the left orbital floor, lateral wall and anterior wall of the left sinus. The lesion occupied the whole of the left antrum and nasal cavity displacing the nasal septum. There was no involvement

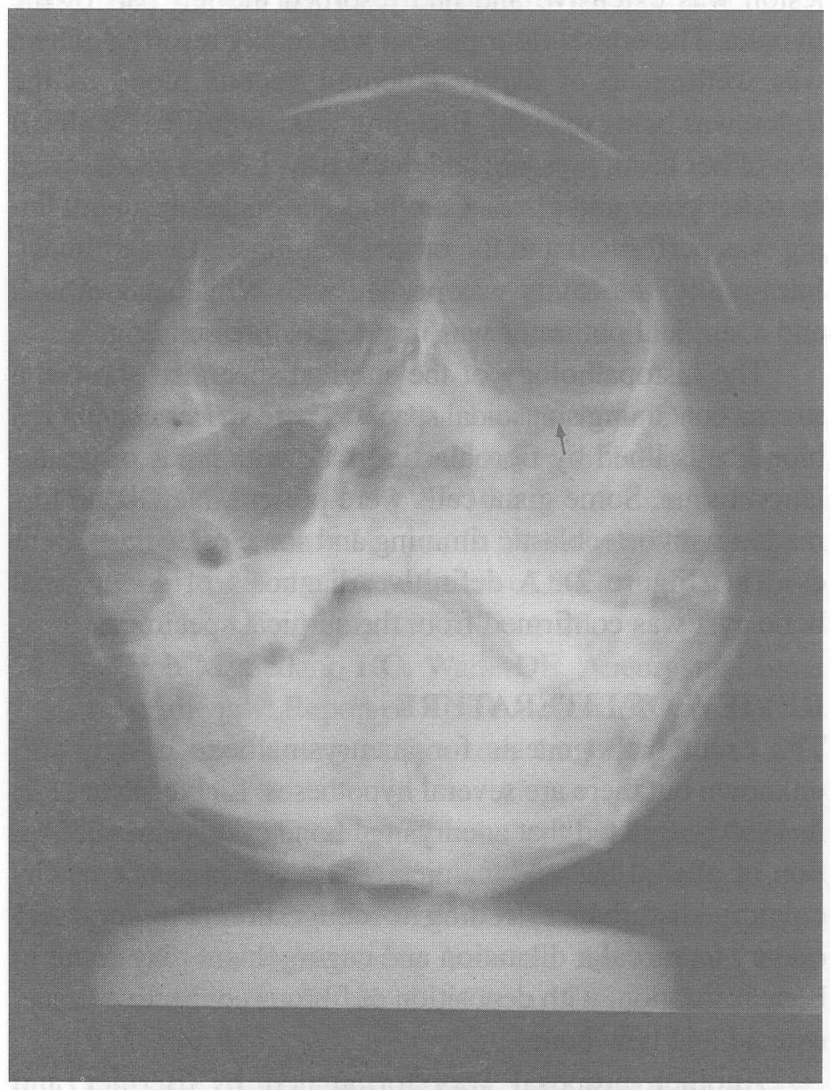

Figure 1. A radiograph showing a radio-opaque mass in the left antrum. Note the discontinuity of the left infra-orbital rim(arrow). 
of the carotid arteries, jugular veins and the neck nodes were not enlarged.

A dark coloured blood like fluid was aspirated from the lesion. A biopsy of the intra-oral lesion was reported as inconclusive and was composed of fragments of granulation tissue, fibroblastic proliferation, bone with osteoclastic activity and extravasated blood. Based on all the clinical and histological information, a provisional diagnosis of aneurysmal bone cyst was reached with a need to rule out the possibility of a malignancy.

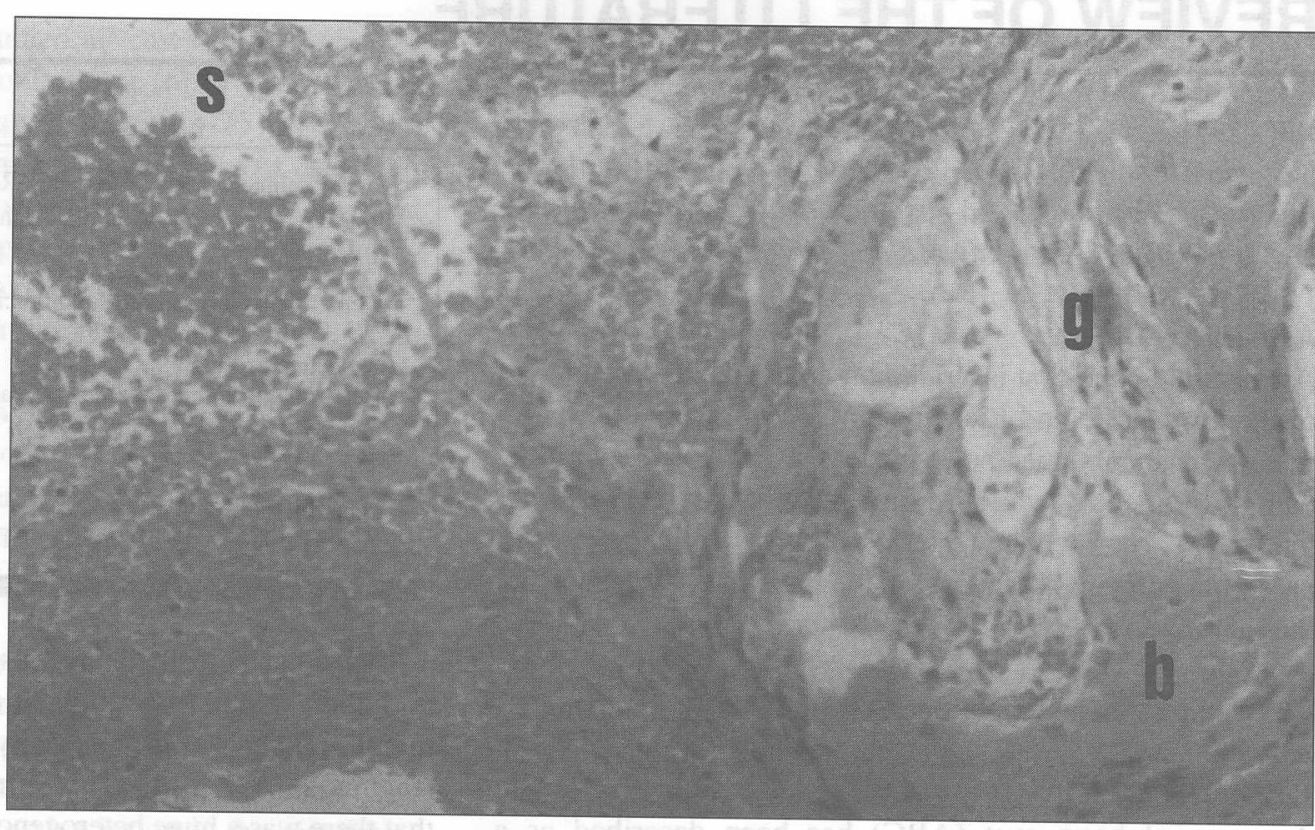

Figure 2. A photo micrograph showing a portion of a large sinusoid(s) filled with blood, a multinucleated giant cell(g) and bone(b). (H \& E, Original magnification - 50X)

A partial maxillectomy was planned under general anaesthesia with facilities for frozen section diagnosis arranged to rule-out malignancy. A Weber-Ferguson incision was carried out and the lesion was exposed. The lesion appeared to be emerging from the infra orbital foremen. The lesion was extensive and had resorbed the left part of the maxilla. The orbital floor present was totally resorbed. There was welling up of darkly coloured venous blood as the lesion was being excised. Bleeding was controlled by elevation of her head, pressure and diathermy. Lesion was excised up to her pterygoid plates. Careful dissection of the antral lining was performed and the orbital hammock was left intact. Intra-orally, the cavity was packed with Whitehead varnish and a surgical obturator was inserted before suturing.

The histopathology of the surgical specimen showed a stroma containing sinusoidal spaces. These spaces contain red blood cells lined by fibroblastic tissue with areas of granulation tissue. Some giant cells were present. New bone formation with osteoblastic rimming and some osteoclasts were evident (Figure 2). A definitive diagnosis of aneurysmal bone cyst was confirmed from the surgical specimen.

\section{REVIEW OF LITERATURE}

The exact pathogenesis for aneurysmalbone cyst is still unknown but there are several hypotheses. Lichtenstein $(1,2)$ in 1950 postulated that aneurysmal bone cyst is a manifestation of altered haemodynamics. There is a presence of circulatory disturbance leading to congestion. Pressure secondary to vascular dilatation and engorgement may result in bone resorption, with deposition of fibrous connective tissue, osteoid and new bone.

Another proposal was formulated by Bernier and Bhaskar (2) who suggested that aneurysmal bone cyst though having nothing in common with giant cell turnout of bone, resembles the central giant cell reparative granuloma of the

jaws. The only deference between the two is the presence of blood-containing spaces. They further suggested that both lesions represent overzealous attempts of the connective tissue to replace a haematoma (possibly arising from trauma) in the bone marrow. If the haematoma maintains a circulatory connection with the damaged vessel, an $\mathrm{ABC}$ results. If it is obliterated, then the lesion is a giant cell reparative granuloma.

A third hypothesis was given by Biesecker et al (1) where they proposed that a primary bone lesion initiates an osseous, arteriovenous malformation and thereby creates, via its haemodynamic forces, a secondary reactive lesion of the bone. This leads to the production of an abnormal vascular component, an arteriovenous fistula by the precursor lesion of the bone. The expansile haemodynamics of the fistula would erode and resorb adjacent bone producing a labyrinth of vascular channels bounded by an expanding periosteal shell of bone. The osseous reparative processes would produce reactive giant cells and active stromal cells lining vascular passages surrounded by extensive fibroblastic proliferation and bone formation.

Struthers and Shear (3) also partly supported the hypothesis that the $\mathrm{ABC}$ is secondary to a primary bone lesion and the haemodynamic theory where they believed that the $\mathrm{ABC}$ was a result of a secondary change in a central giant cell granuloma. They observed that central giant cell granuloma appears to have a propensity to form microcysts because of its loose, fibrillar connective tissue stroma. Localized areas of relative ischaemia in the stroma lead to intercellular oedema and microcysts formation. These microcyst tend to enlarge because of further collapse of the stroma and coalesce with each other. Enlargement also occurs as a result of haemodynamic or osmotic forces. Rupture of thin walled vessels causing haemorrhage into the microcysts occurs because of loss of stromal support around the vessels. With the 
expansion of these spaces, pressure resorption of the surrounding medullary bone occurs leading ultimately to endosteal resorption of the cortical plates. Once the cortical plates are reduced to only a thin shell of bone, blow out of the lesion may occur, with its thin bony shell lifted.

Further to the theory that $\mathrm{ABC}$ was secondary to a primary bone lesion, Hillerup and Hjorting-Hansen (4) suggested that aneurysmal bone cyst, central giant granuloma and traumatic bone cyst were all related lesions. Minute trauma or the presence of unidentified small aneurysmal enlargements may result in an intramedullary bleeding leading to a formation of a haematoma. Differentiation of the haematoma is dependent on the blood supply. Among the lesions that have been associated with $\mathrm{ABC}$ are ossifying fibroma, fibrous dysplasia, cementifying fibroma, giant cell granuloma (5-8).

Clinically, the lesion usually occurs in young adults below 20 years of age $(2,9,10)$ and there does not seem to be any marked sex predilection (2). Although, Tillman et al (11), showed a slight preponderance towards females. Both jaws are affected but more so in the mandible compared to the maxilla. It is usually found in the body and ramus of the mandible $(12,13)$. So far, there have only been 2 cases reporting the involvement of the zygoma (14). An history of trauma could be present in some cases $(3,15)$. Commonly it presents as a swelling of the overlying soft tissues due to bony expansion, which may be rapid in onset. Pain or tenderness may or may not be present. The consistency may be of bony hard or as a firm and rubbery mass. Crepitus may be noted. This lesion has been known to displace tech but tooth vitality is not violated though there has been a case reported where root resorption was present (16). There could be complaints of trismus or TMJ pain possibly due to impingement of the lesion on the joint capsule (13).

Radiographically, aneurysmal bone cyst may appear as a unilocular or multilocular radiolucency with expansion and thinning of the surrounding cortical bone. It has also been described as having a honeycomb or soap bubble appearance since it may be traversed by thin bony septa. But there is no pathognomonic radiographic appearance for $\mathrm{ABC}(8,17)$. However, most cases in the jaws that had been reported in the literature were radioluscent except for one case which was radioopaque (18).

There is no uniform treatment and management of $\mathrm{ABC}$ due to its varied nature. The usual treatment of choice is curettage as it is a benign lesion $(2,3,5)$. The failure to remove the lesion completely has been associated with a recurrence, although there has been a report of a case whereby the lesion regressed spontaneously (18). Some authors have also recommend supplementing curettage with cryotherapy $(3,5,11)$. The defect can be filled up with bone chips prior to cryosurgery (5). Segmental resections are performed with immediate bone grafting if the lesions have been found to be extensive and cause functional and cosmetic deformities (16). Radiation is not recommended as sarcomatous change has been reported in these lesions after irradiation (11).

A high recurrence rate of $53-66 \%$ has been reported
$(1,3,17)$ for $\mathrm{ABC}$ in the jaws. Therefore, a close follow up of the cases is recommended (5).

\section{DISCUSSION AND CONCLUSION}

The age of this patient was in the range of the reported age for $\mathrm{ABC}$. The case presented here poses an initial diagnostic problem due to the inability of obtaining a deeper biopsy because of excessive bleeding. The superficial biopsy did not contain all the features required for a diagnosis of aneursymal bone cyst. A differential diagnosis of $\mathrm{ABC}$ or haemangioma was made in view of the presence of dark blood-like fluid on aspiration. Although the initial biopsy findings was inconclusive, the presence of granulation tissue, osteoclastic activities and extravasated blood with no excessive presence of normal blood vessels in the precluded the diagnosis of haemangioma.

Radiographically, this lesion was not typical of $\mathrm{ABC}$ in view of the fact that it was located in the maxillary antrum. Instead of the usual radiolucencies in the jaws, this lesion presents as a radiopacity in the maxillary antrum.

The treatment plan was made on the provisional diagnosis of $\mathrm{ABC}$ upon clinical and radiographic investigation. Partial maxillectomy was initially planned for this patient. However, during the surgery most of the bone had resorbed. Therefore, the lesion was excised. The frozen section that was sent reported a giant cell lesion with no evidence of malignancy. Upon excision, there was welling up of blood leading us to believe that the lesion was an aneursymal bone cyst. This diagnosis was further confirmed by the histopathological report.

\section{REFERENCES}

1. Biesecker JL, Marcove RC, Huvos AG, Mike V. Aneursymal Bone Cysts: A clinicopathological study of 66 cases. Cancer; September 1970: 615-25.

2. Bemier JL, Bhaskar SN. Aneursymal Bone Cysts of the mandible; Oral Surg Oral Med Oral Path 1958; 11 (9): 1018-1028.

3. Struthers PJ, Shear M. Aneursymal bone cysts of the jaws: Clinicopathological Features and Pathogenesis. Int J Oral Surg 1984; 13: 85-100.

4. Hillerup S, Hjorting-Hansen E . Aneurysmal bone cysts - simple bone cyst, two aspects of the same pathologic entity ? Int J Oral Surg 1978; 7: 16-22.

5. El Deeb M, Sedano HO, Waite DE. Aneurysmal bone cyst of the jaw: Report of a case associated with fibrous dysplasia and review of literature. Int J Oral Surg 1980; 9: $301-311$.

6. Robinson PD. Aneurysmal bone cyst: A hybrid lesion? Br J Oral Maxilbfac Surg. 1985 ; 23 220-226.

7. Buraczewski J, Dabska M. Pathogenesis of Aneurysmal Bone Cysts: Relationship between Aneurysmal bone cyst and Fibrous Dysplasia of bone. Cancer; September 1971: 597-604.

8. Oliver LP. Aneurysmal Bone Cysts: Report of a case. Oral Surg; January 1973: 67-76.

9. Reyneke JP. Aneurysmal bone cyst of maxilla. Oral Surg, March 1978; 45 (3): 441-447. 
10. Boyd RC. Aneursymal bone cysts of the jaws. Br J Oral Surg ( 1978 - 79); 16: 248-253.

11. Tillman BP, Dahlin DC, Lipscomb PR, Stewart JR. Aneursymal Bone Cyst: An Analysis of 95 cases. Mayo Clin Proc 1968; 43: 478-485.

12. Zachariades N, Vairaktaris E, Mezitis M, Triantafyllou D, Papavassiliou D, Economopoulou P. Aneurysmal bone cysts of the jaws: Review of literature and report of 2 cases. Int J Oral Maxillofac Surg 1986;15:534-540.

13. Toljanic JA, Lechewski E, Huvos AG, Strong EW, Schweiger JW. Aneursymal bone cysts of the jaws: A case study and review of literature. Oral Surgery 1987; 64 (1): 72-77.

14. Carmichael F, Malcolm AJ, Ord RA. Aneurysmal bone cyst of the zygomatic bone. Oral Surg Oral Med Oral
Path 1989; 68: 558-62.

15. Motamedi MHK, Yazdi E. Aneurysmal bone cyst of the jaws: Analysis of 11 cases. J Oral Maxillofac Surg 1994; 52: 471-475.

16. Hardee PSGF, Nicholas MW, Morgan PR . Aneurysmal bone cyst of the maxilla - an association with tooth resorption. J Cranio-Maxillo Fac Surg 1992; 20: 266 269.

17. Steidler NE, Cook RM, Reade PC. Aneusymal bone cysts of the jaws: A case report and review of the literature. Br J Oral Surg 1978-1979; 16: 254-261.

18. Bataineh AB. Aneurysmal Bone Cysts of the Maxilla: A Clinicopathologic Review. J Oral Maxillofac Surg 1997; 55: $1212-1216$ 